\title{
Effects of Dust on Radiation Transfer in the Martian Atmosphere (II)
}

\author{
Heating due to Absorption of the Visible Solar Radiation and Importance \\ of Radiative Effects of Dust on the Martian Meteorological Phenomena
}

\author{
By Shigeru Moriyama
}

The Physical Science Laboratories, Nihon University at Narashino, Funabashi, Chiba, Japan

(Manuscript received 20 January 1975, in revised form 6 May 1975)

\begin{abstract}
The complex index of refraction of the Martian dust particles suspended in the atmosphere is estimated. Using this parameter, we solve the multiple scattering equations and investigate quantitatively heating of the Martian atmosphere due to absorption of the visible solar radiation. Our results show that the atmosphere is strongly heated up by absorption of solar radiation due to dust, and that the thermal structure of the Martian atmosphere would be almost determined by the balance between heating and cooling caused by radiative effects of dust. It is also pointed out that the thermal effects due to dust would induce strong thermal tide. Analyses of the Mariner 9 data indicate fairly good agreement with our results. A new general circulation model for Mars including the thermal effects of dust should be required at the moment.
\end{abstract}

\section{Introduction}

There are several evidences which imply that a fairly large amount of dust would be suspended in the Martian atmosphere. Not only great dust storms but also strong slope winds or dust devils, which frequently occur on the Mars, would supply dust into the atmosphere unceasingly (Gierasch and Goody, 1973; Blumsack et al., 1973; Leovy et al., 1973). However, most of studies on the Martian atmospheric phenomena have been carried out on the basis of assumption of dust-free atmosphere (e.g., Gierasch and Goody, 1968; Leovy and Mintz, 1969). Between these theoretical results and the recent Martian observational results, some discrepancies are noticed. For example, the vertical temperature profiles indicate more stable features than those predicted by radiative-convective results obtained from dust-free atmosphere. And strong tidal components of temperature, pressure and wind fields exist in the different form from ones of the numerical simulation performed by Leovy and Mintz (1969) under dust-free condition, especially during dust-storm events (e.g., Pirraglia and Conrath, 1974). The thermal tide is likely to be strongly related with the thermal effects due to dust. Absorption of solar radiation due to dust is also a very important term as energy source of atmospheric motion (Gierasch and Goody, 1973; Golitsyn, 1973; Hess, 1973: Leovy et al., 1973)

In the previous paper (Moriyama, 1974), we studied the effect of dust on infrared radiation transfer, and pointed out its importance to the thermal structure of the Martian atmosphere. As an extension of our study on radiative effects of dust, now we investigate quantitatively heating of the Martian atmosphere due to absorption of the visible solar radiation in the present paper. Combining it with our previous study, we will indicate that dust suspended in the atmosphere would play essential roles on the Martian atmospheric phenomena and also on thermal structure through its radiative effects, and propose that new general circulation models laying stress on dust should be required in place of existing dustfree model.

In the next section we discuss the complex index of refraction of the Martian dust particles which is one of the most important parameters for optical properties. Using this parameter, we solve the multiple scattering equations and estimate 
heating rate caused by absorption of visible solar radiation due to dust in Section 3. In Section 4, results of the numerical calculation and discussions are presented.

\section{Complex refractive index of dust}

Absorption coefficient of dust depends largely upon the imaginary part of its refractive index. However, anyone does not know the exact value of complex refractive index of the Martian dust particles. Moreover, it seems that we have no enough knowledge on the values of complex index of refraction of various minerals. But, if using the single scattering albedo of the Martian dust particles obtained from Mariner's observations, we may be able to estimate this important optical parameter on the Martian dust particles as follows.

Absorption coefficient of dust particles $\beta_{a b s}$ is expressed as the difference between extinction coefficient $\beta_{e x t}$ and scattering coefficient $\beta_{s c}$ :

$$
\beta_{a b s}=\beta_{e x t}-\beta_{s c} .
$$

Using Mie's theory, efficiency factors for extinction and scattering coefficients, $Q_{e x t}$ and $Q_{s c}$ respectively, can be written as the function of complex index of refraction $m\left(=\tilde{r}_{\lambda}-i{\tilde{r_{\lambda}}}^{\prime}\right)$, particle radius $r$ and wavelength $\lambda$ (e.g., Goody, 1964):

$$
Q_{e x t}(x, m)=\left(2 / x^{2}\right) \sum_{n=1}^{\infty}(2 n+1) \operatorname{Re}\left\{a_{n}+b_{n}\right\},
$$

and $Q_{s c}(x, m)=\left(2 / x^{2}\right) \sum_{n=1}^{\infty}(2 n+1)\left\{\left|a_{n}\right|^{2}+\left|b_{n}\right|^{2}\right\}$,

where $x=2 \pi r / \lambda, a_{n}$ and $b_{n}$ are described using Bessel functions as follows (Deirmendjian et al., 1961):

$$
\begin{aligned}
a_{n} & =\left\{\left(A_{n} / m+n / x\right) J_{n+1 / 2}(x)-J_{n-1 / 2}(x)\right\} \\
& \div\left\{\left(A_{n} / m+n / x\right)\left(J_{n+1 / 2}(x)+i(-1)^{n} J_{-n-1 / 2}(x)\right)\right. \\
& \left.-J_{n-1 / 2}(x)+i(-1)^{n} J_{-n+1 / 2}(x)\right\}, \\
\text { and } b_{n} & =\left\{\left(m A_{n}+n / x\right) J_{n+1 / 2}(x)-J_{n-1 / 2}(x)\right\} \\
& \div\left\{\left(m A_{n}+n / x\right)\left(J_{n+1 / 2}(x)+i(-1)^{n} J_{-n-1 / 2}(x)\right)\right. \\
& \left.-J_{n-1 / 2}(x)+i(-1)^{n} J_{-n+1 / 2}(x)\right\},
\end{aligned}
$$

where

$$
A_{n}(m x)=-(n / m x)+\left\{J_{n-1 / 2}(m x) / J_{n+1 / 2}(m x)\right\} .
$$

Thus, $\beta_{e x t}$ and $\beta_{s c}$ are calculated from the following expressions as the function of $\lambda$ and $m$ :

$$
\beta_{e x t}=\pi \int r^{2} Q_{e x t} d n(r)
$$

and

$$
\beta_{s c}=\pi \int r^{2} Q_{s c} d n(r)
$$

where, as particle size distribution $d n / d r$, we reffered to the same one as that of the atmosphere over the terrestrial desert (e.g., Peterson, 1968; Peterson and Weinman, 1969). The same distribution was also used in our calculation of cooling rate due to dust in infrared regions (see, eq. (9) in our previous paper, 1974).

Leovy et al., (1972) indicated that the single scattering albedo $\widetilde{\omega}$ of the Martian dust particles has value between 0.68 and 0.70 in the visible region from observations of the Martian brightness by Mariner 9 during dust storm. $\tilde{\omega}$ can be written using $\beta_{s c}$ and $\beta_{\text {ext }}$ :

$$
\widetilde{\omega}=\beta_{s c} / \beta_{e x t} .
$$

Utilizing eqs. (1) to (9), we can search suitable complex index of refraction which fits the above observational values on $\tilde{\omega}$ by iteration method. Thus, the following value on $m$ are obtained in the visible region:

$$
m=1.55-0.033 i,
$$

where as real part of refractive index we adopt the typical value of materials supposed to be composing the Martian dust particles, which has presumably the value between 1.5 and 1.6. For example, an aggregate refractive index of montmorillonite, which is supposed to be one of the important compositions of the Martian dust particles (Hunt et al., 1973), ranges from 1.5 to 1.64 (Mason and Berry, 1968). In our calculation 1.55 is assumed.

It is expected that the value of complex index of refraction of the Martian dust may be larger than that of the terrestrial aerosol, because the effective composition of the Martian dust particles on absorption of solar radiation is thought to be such minerals as montmorillonite. It seems that the above resultant value on $m$ would not differ from the exact.one so much.

\section{Basic equations for radiative transfer}

Utilizing the complex index of refraction of dust for the calculation of the optical thickness of dust layer and of the phase function, we can 
compute the heating rate of atmosphere by absorption of solar radiation due to dust.

The basic equation describing the diffuse intensity of solar radiation in azimuthally independent case can be written as

$$
\eta \frac{d I_{\nu}(\tau, \eta)}{d \tau}=I_{\nu}(\tau, \eta)-S_{\nu}(\tau, \eta)
$$

where $S$ is the source function defined by

$$
\begin{aligned}
S_{\nu}(\tau, \eta) & =\frac{1}{2} \int_{-1}^{1} P_{\nu}\left(\tau ; \eta, \eta^{\prime}\right) I_{\nu}\left(\tau, \eta^{\prime}\right) d \eta^{\prime} \\
& +\frac{F_{\nu}}{4} e^{-\tau / \eta_{0}} P_{\nu}\left(\tau ; \eta,-\eta_{0}\right) .
\end{aligned}
$$

In these equations, $I$ represents the intensity, $\tau$ the optical thickness, $P$ the phase function independent of the azimuthal angle, $F$ the solar flux, $\eta$ and $\eta_{0}$ the cosine of the emergent and the solar zenith angles, respectively. The subscript $\nu$ denotes the wavenumber dependence.

The surface reflection is assumed to follow the Lambert law of reflection. Then, the boundary conditions can be written as

$$
\left.\begin{array}{l}
I_{\nu}(0,-\eta)=0 \\
I_{\nu}\left(\tau_{s}, \eta\right)=I_{s \nu}
\end{array}\right\},
$$

where $I_{s}$ is the intensity of the reflected radiation from the Lambert surface at $\tau=\tau_{s}$. Using this boundary conditions, we can obtain the formal solutions of eq. (11) as follows:

$$
I_{\nu}(\tau,-\eta)=\int_{0}^{\tau} S_{\nu}\left(\tau^{\prime},-\eta\right) e^{-\left(\tau-\tau^{\prime}\right) / \eta} \frac{d \tau^{\prime}}{\eta},
$$

and $I_{\nu}(\tau, \eta)=I_{s \nu} e^{-\left(\tau_{s}-\tau\right) / \eta}+\int_{\tau}^{\tau_{s}} S_{\nu}\left(\tau^{\prime}, \eta\right) e^{-\left(\tau^{\prime}-\tau\right) / \eta} \frac{d \tau^{\prime}}{\eta}$.

To evaluate eqs. (14) and (15), we used the same method of an iterative numerical integration as Yamamoto et al. (1974). If $I(\tau,-\eta)$ and $I(\tau, \eta)$ are obtained, the downward and upward fluxes of the diffuse radiation field at any given level can be readily written as

$$
F_{\nu} \downarrow(\tau)=2 \pi \int_{0}^{1} I_{\nu}(\tau,-\eta) \eta d \eta,
$$

$$
\text { and } \quad F_{\nu} \uparrow(\tau)=2 \pi \int_{0}^{1} I_{\nu}(\tau, \eta) \eta d \eta
$$

Since the flux of the direct solar radiation at $\tau$ is $\pi F_{v} \eta_{0} e^{-\tau / \eta_{0}}$, the net flux $F_{N}(\tau)$ is given by

$$
F_{N \nu}(\tau)=\pi F_{\nu} \eta_{0} e^{-\tau / \eta_{0}}+F_{\nu} \downarrow(\tau)-F_{\nu} \uparrow(\tau) .
$$

The rate of temperature change in the atmosphere due to absorption of the visible solar radiation is now obtained from the following relation,

$$
\frac{d T(z)}{d t}=\frac{1}{c_{p} \rho(z)} \frac{d f_{N}(z)}{d z},
$$

where $t$ is time, $c_{p}$ the specific heat at constant pressure, $\rho$ the density of the atmosphere at $z$ in height, and $f_{N}(z)$ the total net flux integrated over the visible region from 0.3 to $0.8 \mu$ at $\tau=\tau(z)$.

\section{Results and discussions}

In the actual calculation to obtain the solution of the equation of radiative transfer, we divided the whole dusty atmospheric layer from the surface to $10 \mathrm{~km}$ in height into 39 sublayers. And we approximated the continuous radiation field at each point by 20 discrete distribution according to Yamamoto et al. (1974). The albedo of surface is assumed to be 0.15 .

Fig. 1 shows the results obtained from the above calculations, for the both cases of northern summer solstice and equinox. Abscissa and ordinate present heating rate and height, respectively. And $\varphi$ denotes latitude. Cosine of the solar zenith angles for the cases of various latitudes $\left(62^{\circ},-6.5^{\circ},-43.5^{\circ}, 30^{\circ}, 85.5^{\circ}\right)$ are $0.45,0.55$, $0.25,0.55$ and 0.05 , respectively.

Three cases on dust concentration, which are denoted by (A), (B) and (C), are computed. The first case (A) corresponds to that of very high concentration up to $800 \times 10^{-6} \mathrm{~g} \cdot \mathrm{m}^{-3}$ near the ground (Fig. 1(a)). Total optical depth averaged over the visible region $\bar{\tau}_{0}$ for this case is about 1.4. The second is of lower dust density up to $80 \times 10^{-6}$ $\mathrm{g} \cdot \mathrm{m}^{-3}$ (Fig. 1 (b)). $\quad \bar{\tau}_{0}$ for the case (B) is about 0.14. The third is of very low concentration up to $8 \times 10^{-6} \mathrm{~g} \cdot \mathrm{m}^{-3}$ (Fig. 1(c)). $\quad \bar{\tau}_{0}$ for this case is some 0.014 .

Fig. 1 shows the following results:

i) During dust storm events, the Martian atmosphere is strongly heated up by absorption of solar radiation due to dust. Especially, our results indicate the heating rate of more than $100 \mathrm{~K}$ /day within lower layers in strongly and long insolated regions. The large heating rate of $100 \mathrm{~K} /$ day would be enough amount for dust storm to be developed, according to Gierasch and Goody (1973). 
ii) As shown in Fig. 1 (c), thermal effects of dust is large even for the condition of very low dust concentration. Therefore, heat budget of the Martian atmosphere should be investigated by consideration of the effects not only by atmospheric radiative gas but also by dust, even if the atmosphere has a fairly clear condition.

iii) Our calculations (Moriyama, 1974) show that the infrared radiative cooling rate due to dust is a few tens degrees or more per day in the dusty layers, while cooling rate due to $\mathrm{CO}_{2}$ is a few degrees per day. From these results, we may be able to say that the thermal structure of the Martian atmosphere would be almost determined by the balance between solar absorption heating and infrared radiative cooling due to dust. At the dust-storm case, it appears to be undoubtedly the fact, though small contribution due to

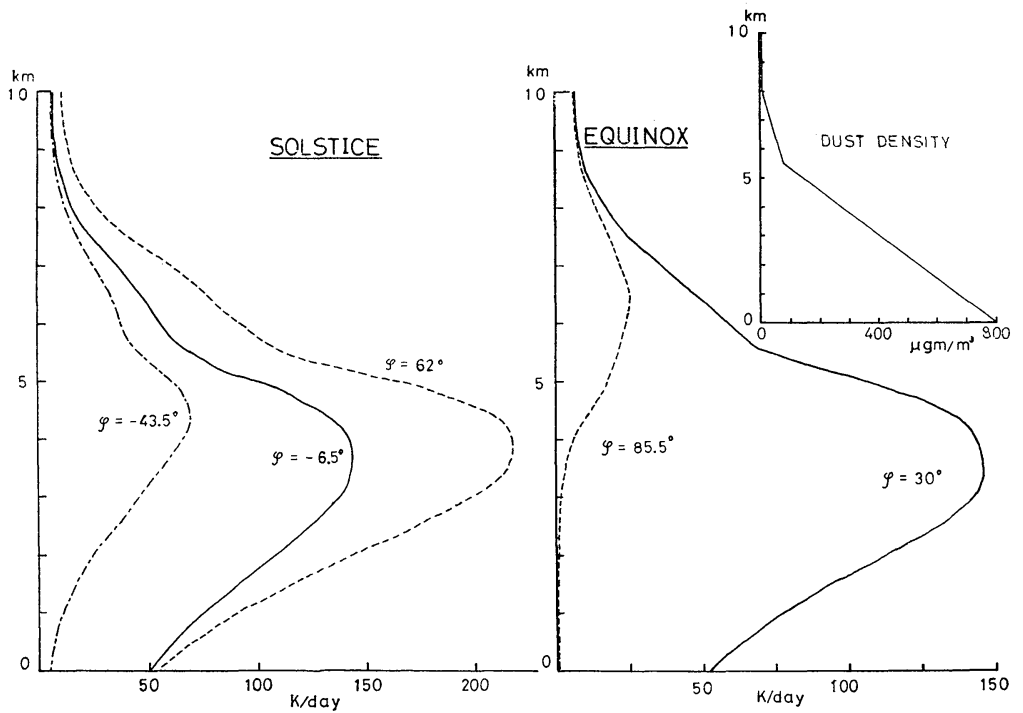

Fig. 1 (a). Heating rate ( $\mathrm{K} /$ day) due to absorption of the visible solar radiation by dust for the case of heavy dusty condition. The results for the Northern summer solstitial (left side) and the equinoctial (right side) seasons are presented. $\varphi$ denotes latitude. Vertical dust density profile assumed in these calculations is also shown in the right-hand figure.
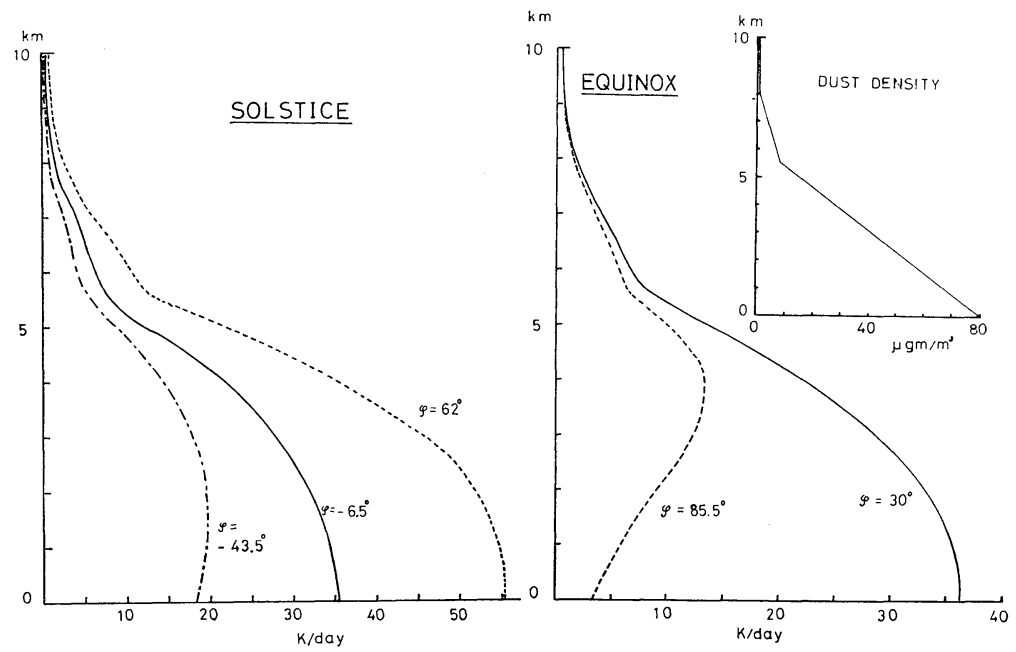

Fig. 1 (b). Same as Fig. 1 (a) but for the case of dusty condition. 

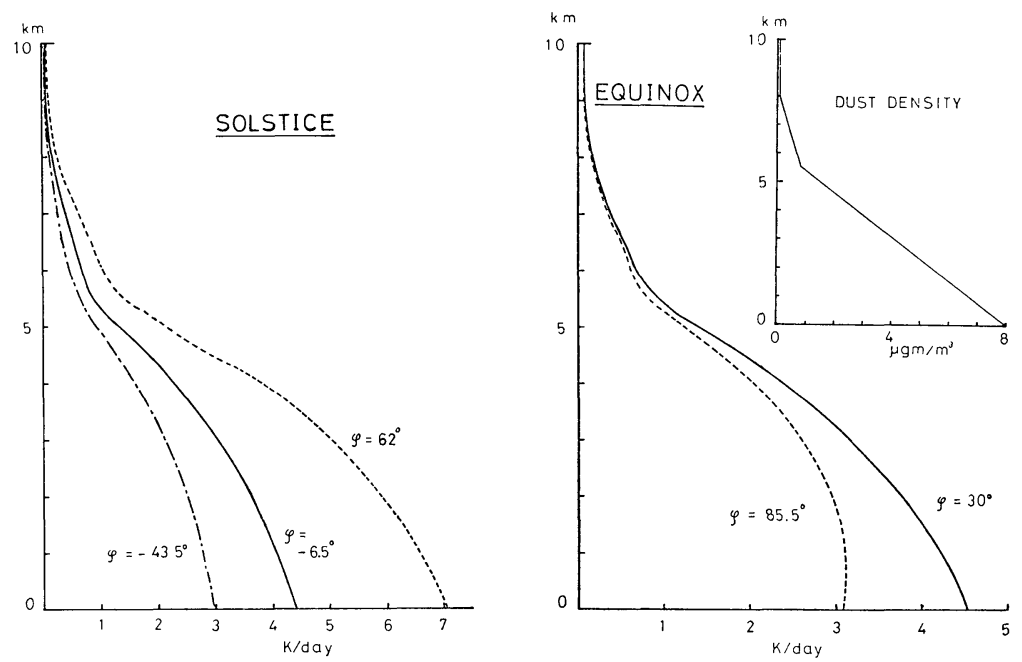

Fig. 1 (c). Same as Fig 1 (a) but for the case of very low dust concentration.

dynamical transport of heat is also considered. Vertical turbulent heat transport is supposed to be very small, because the observed vertical temperature profiles indicate very stable features in Mariner 6, 7 and 9 observations. If the atmosphere is stably stratified, turbulence is strongly suppressed and has associated value of the vertical eddy diffusivity less than the effective radiative diffusivity (Gierasch and Goody, 1968). Consequently, the effect due to turbulence would be negligible, compared with the fact that dust has very large contribution to the thermal condition of the Martian atmosphere as shown above.

It is very important that the thermal effects of dust is large. For, it seems that hitherto we have underestimated the radiative effects of dust in the Martian atmosphere. However, dust plays indeed essential roles on the atmospheric thermal structure. Moreover, it is likely for the Martian great dust storm to be developed by absorption of solar radiation due to dust, as pointed out by some investigators (e.g., Gierasch and Goody, 1973; Golitsyn, 1973; Leovy et al., 1973; Hess, 1973). In the earth's atmosphere water vapor plays the similar roles through its latent heat release. If signifying that the meteorology of the earth is characterized by water vapor, we could say that the Martian meteorology should be based on dust in the same sence.

Tables 1 to 3 indicate disposition of solar radiation in the dusty atmosphere for the cases of (A), (B) and (C) at each latitude respectively. Our results show that the planetary albedo will decrease in the dusty atmosphere, and that fairly amount of solar radiation will be directly trapped in the atmosphere. This seems to indicate much more

Table 1. Disposition of the visible solar radiation in the Martian atmosphere in the case of heavy dusty condition.

\begin{tabular}{c|r|r|r|r|r}
\hline \multicolumn{1}{c|}{ Leason } & \multicolumn{2}{|c|}{ Northern summer solstice } & \multicolumn{2}{c}{ Equinox } \\
\hline \multicolumn{1}{c|}{ Latitude } & $62^{\circ}$ & $-6.5^{\circ}$ & $-43.5^{\circ}$ & $30^{\circ}$ & $85.5^{\circ}$ \\
\hline $\begin{array}{l}\text { Incident solar flux } \\
\text { Upward flux at the top of the }\end{array}$ & 2.5 & 2.3 & 3.2 & 2.3 & 6.1 \\
$\quad \begin{array}{l}\text { atmosphere } \\
\text { Total downward flux transmitted } \\
\text { to the surface }\end{array}$ & 9.5 & 13.9 & 2.5 & 13.9 & 0.7 \\
$\begin{array}{c}\text { Solar flux diffusely transmitted } \\
\text { to the surface }\end{array}$ & 3.1 & 3.8 & 1.6 & 3.8 & 0.7 \\
$\begin{array}{c}\text { Solar energy trapped in the } \\
\text { atmosphere by dust }\end{array}$ & 89.5 & 85.8 & 94.7 & 85.8 & 93.3 \\
\hline
\end{tabular}


Table 2. Same as Table 1 but for the case of dusty condition.

\begin{tabular}{c|r|r|r|r|r}
\hline Season & \multicolumn{2}{|c|}{ Northern summer solstice } & \multicolumn{2}{|c|}{ Equinox } \\
\hline \multicolumn{1}{c|}{ Latitude } & $62^{\circ}$ & $-6.5^{\circ}$ & $-43.5^{\circ}$ & $30^{\circ}$ & $85.5^{\circ}$ \\
\hline Incident solar flux & $100 \%$ & $100 \%$ & $100 \%$ & $100 \%$ & $100 \%$ \\
$\begin{array}{c}\text { Upward flux at the top of the } \\
\text { atmosphere }\end{array}$ & 10.3 & 10.5 & 9.3 & 10.5 & 7.1 \\
$\begin{array}{c}\text { Total downward flux transmitted } \\
\text { to the surface }\end{array}$ & 76.3 & 80.3 & 61.4 & 80.3 & 13.4 \\
$\begin{array}{c}\text { Solar flux diffusely transmitted } \\
\text { to the surface }\end{array}$ & 2.9 & 2.7 & 3.6 & 2.7 & 5.2 \\
$\begin{array}{c}\text { Solar energy trapped in the } \\
\text { atmosphere by dust }\end{array}$ & 24.9 & 21.2 & 38.5 & 21.2 & 81.6 \\
\hline
\end{tabular}

Table 3. Same as Table 1 but for the case of very low dust concentration.

\begin{tabular}{c|c|r|r|r|r}
\hline Season & \multicolumn{2}{|c|}{ Northern summer solstice } & \multicolumn{2}{|c}{ Equinox } \\
\hline Latitude & $62^{\circ}$ & $-6.5^{\circ}$ & $-43.5^{\circ}$ & $30^{\circ}$ & $85.5^{\circ}$ \\
\hline Incident solar flux & $100 \%$ & $100 \%$ & $100 \%$ & $100 \%$ & $100 \%$ \\
$\begin{array}{c}\text { Upward flux at the top of the } \\
\text { atmosphere }\end{array}$ & 14.4 & 14.4 & 14.2 & 14.4 & 13.1 \\
$\begin{array}{c}\text { Total downward flux transmitted } \\
\text { to the surface }\end{array}$ & 97.3 & 97.8 & 95.1 & 97.8 & 77.7 \\
$\begin{array}{c}\text { Solar flux diffusely transmitted } \\
\text { to the surface }\end{array}$ & 0.4 & 0.4 & 0.6 & 0.4 & 2.0 \\
$\begin{array}{c}\text { Solar energy trapped in the } \\
\text { atmosphere by dust }\end{array}$ & 2.9 & 2.4 & 4.9 & 2.4 & 20.9 \\
\hline
\end{tabular}

dependence of the Martian atmospheric phenomena upon insolation than in the dust-free case. It is expected that the general circulation in the dusty case would be considerably different from that in the clear condition.

In fact, some analyses of wind fields based on Mariner 9 observations (e.g., Hanel et al., 1972; Leovy et al., 1973; Pirraglia and Conrath, 1974) under dusty conditions suggest some different features from those of Leovy and Mintz's prediction (1969). The most characteristic point is existence of strong tidal components in temperature, wind and pressure fields, which appear to be combined with strong solar heating due to dust. Recently Pirraglia and Conrath (1974) have calculated the Martian atmospheric tidal pressure and wind fields, using temperature fields derived from the Mariner 9 infrared spectroscopy experiment. Their results indicate the large diurnal amplitude of tidal component in the temperature, surface pressure, wind and atmospheric heating fields. Especially, the result is very significant that dynamic heating is a small part of the total atmospheric heating required and the heating appears to be primally a radiative effect. To account for the required atmospheric heating at sub-solar latitudes and local noon, the energy deposited in the atmosphere would amount to approximately $20 \%$ of the solar flux incident normally on the top of an atmospheric column, and to achieve adequate nighttime cooling an effective atmospheric emissivity of 0.53 would be required. Maximum radiative heating and cooling averaged over the atmospheric column are 12 $\mathrm{K} /$ day respectively. Our results of dusty case (B) is in highly good agreement with these results (Table 2 and Fig. 1 (b)).

Our results also suggest that radiative effects due to dust would produce the strong diurnal temperature fluctuations. Thus our results give an important suggestion to the reason why such a large radiative effect is caused, because adequate amount of dust has enough effect to deposite more than $20 \%$ of the incident solar flux in the atmosphere and to radiate infrared flux to space during nighttime.

The Mariner 9 infrared interferometer spectrometer data also show that the diurnally varying 
heating is uniform up to some height and vanishes above that level (Hanel et al., 1972). This fact would indicate that the heating is not related to heat transport by thermal convection from lower layers, but to the direct strong absorption of insolation within the atmosphere.

These facts reveal that dust does play very important roles on the Martian atmospheric phenomena, as described above. Our results also seem to show that index of the general circulation would be higher than that discussed under the clear conditions up to now.

The greatest need at the moment are further comprehensive numerical general circulation studies for Mars. Of course, the effects due to dust and also due to topography must be included in that model atmosphere with considerable care.

Our model atmosphere indicates a very strong forward scattering feature. But the feature fairly depends upon the complex refractive index and particle size distribution. Therefore it must be borne in mind that values shown in Tables 1 to 3 might be somewhat changed from the presented ones on this account in future.

\section{Acknowledgements}

The author wishes to thank Professor R. Yamamoto of Kyoto University for careful reading of the manuscript. And the author is also indebted to the members of Planetary Physics Group of the Kwasan Observatory, Kyoto University, for their helpful discussions. Thanks are extended to Dr. S. Ohta of Tohoku University for useful advices on the method of numerical calculation.

\section{References}

Blumsack, S. L., P. J. Gierasch and W. R. Wessel, 1973: An analytical and numerical study of the Martian planetary boundary layer over slopes. $J$. Atmos. Sci., 30, 66-82.

Deirmendjian, D., R. Clasen and W. Viezee, 1961: Mie scattering with complex index of refraction. J. Opt. Soc. Amer., 51, 620-633.

Gierasch, P. J. and R. M. Goody, 1968: A study of the thermal and dynamical structure of the Martian lower atmosphere. Planet. Space Sci., 16, 615-646. and 1973: A model of a Martian great dust storm. J. Atmos. Sci., 30, 169-179.

Golitsyn, G. S., 1973: On the Martian dust storms. Icarus, 18, 113-119.

Goody, R. M., 1964: Atmospheric Radiation: I. Theoretical Basis. Oxford University Press, $436 \mathrm{pp.}$

Hanel, R., B. Conrath, W. Hovis, V. Kunde, P. Lowman, W. Maguire, J. Pirraglia, C. Prabhakara, B. Schlachman, G. Levin, P. Straat and T. Burke, 1972: Investigation of the Martian environment by infrared spectroscopy on Mariner 9. Icarus, 17, 423-442.

Hess, S. L., 1973: Martian winds and dust clouds. Planet. Space Sci., 21, 1549-1557.

Hunt, G. R., L. M. Logan and J. W. Salisbury, 1973: Mars: Components of infrared spectra and the composition of the dust cloud. Icarus, 18, 459-469.

Leovy, C. and Y. Mintz, 1969: Numerical simulation of the weather and climate of Mars. J. Atmos. Sci., 16, 1167-1190.

, G. A. Briggs, A. T. Young, B. A. Smith, J. B. Pollack, E. N. Shipley and R. L. Wildey. 1972: The Martian atmosphere: Mariner 9 television experiment progress report. Icarus, 17, 373393.

$\longrightarrow$, R. W. Zurek and J. B. Pollack, 1973: Mechanisms for Mars dust storms. J. Atmos. Sci., 30, 749-762.

Mason, B. and L. G. Berry, 1968: Elements of Mineralogy. W. H. Freeman \& Co., 446-447.

Moriyama, S., 1974: Effects of dust on radiation transfer in the Martian atmosphere (I) -on infrared radiative cooling-. J. Meteor. Soc. Japan, 52, 457-462.

Peterson, J. T., 1968: Measurement of atmospheric aerosols and infrared radiation over Northwest India and their relationship. ONR Tech. Rept. No. 38, Dept. of Meteorology, University of Wisconsin. $165 \mathrm{pp}$.

- and J. A. Weinman, 1969: Optical properties of quartz dust particles at infrared wavelengths. J. Geophys. Res., 74, 6947-6952.

Pirraglia, J. A. and B. J. Conrath, 1974: Martian tidal pressure and wind fields obtained from the Mariner 9 infrared spectroscopy experiment. $J$. Atmos. Sci., 31, 318-329.

Yamamoto, G., M. Tanaka and S. Ohta, 1974: Heating of the lower troposphere due to absorption of the visible solar radiation by aerosols. J. Meteor. Soc. Japan, 52, 61-68. 


\section{放射伝達に及ぼす火星大気中のタストの効果（その 2)}

一太陽光吸収による加熱と，火星の気象学的現象へのダストによる放射効果の重要性

森山茂

日本大学理・工系習志野校舎, 物理教室

火星大気中に浮遊するダストの複素屈折率を評価し, それを使って, 多重散乱の方程式を解くことにより, 可視領 域での太陽光吸収による火星大気の加熱を定量的に求めた。 その結果, 大気はダストによる太陽光吸収によって, 強 烈に暖められていること，及び，火星大気の熱的構造は，ほぼ，ダストの放射効果によって生ずる加熱と冷却のバラ ンスで決っているらしいことが分った。 また，ダストによる熱的な効果は強い熱潮汐を引起すであるうことが指摘さ れている. マリナー 9 号のデータの解析は，われわれの結果をよく裏付けているように見觉る．ダストの熱的効果を 含む新しい火星の大気大循環モデルが，今や要請されねばならない. 